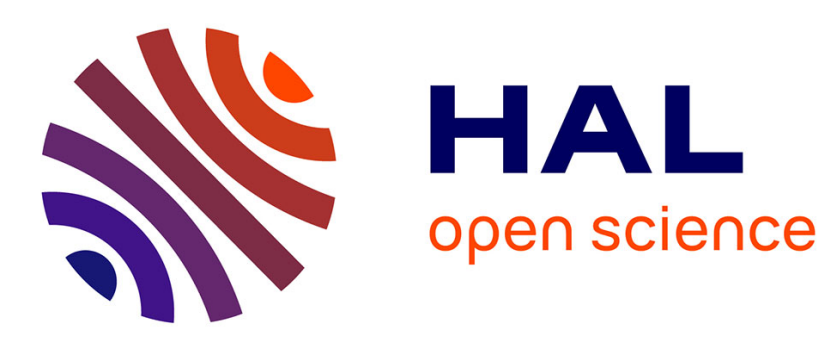

\title{
Collective Dislocation Dynamics and Avalanches during Fatigue of Aluminum
}

\author{
W. Ben Rhouma, Stéphanie Deschanel, J. Weiss
}

\section{To cite this version:}

W. Ben Rhouma, Stéphanie Deschanel, J. Weiss. Collective Dislocation Dynamics and Avalanches during Fatigue of Aluminum. International Conference on Numerical Analysis and Applied Mathematics (ICNAAM 2011), Sep 2011, Halkidiki, Greece. 10.1063/1.3637920 . hal-01822575

\section{HAL Id: hal-01822575 \\ https://hal.science/hal-01822575}

Submitted on 18 Jan 2022

HAL is a multi-disciplinary open access archive for the deposit and dissemination of scientific research documents, whether they are published or not. The documents may come from teaching and research institutions in France or abroad, or from public or private research centers.
L'archive ouverte pluridisciplinaire HAL, est destinée au dépôt et à la diffusion de documents scientifiques de niveau recherche, publiés ou non, émanant des établissements d'enseignement et de recherche français ou étrangers, des laboratoires publics ou privés.

\section{다)(1) $(5$}

Distributed under a Creative Commons Attribution - NonCommercial| 4.0 International 


\title{
Collective Dislocation Dynamics and Avalanches during Fatigue of Aluminum
}

\author{
W. Ben Rhouma ${ }^{1,2}$, S. Deschanel ${ }^{1}$ and J. Weiss ${ }^{2, *}$ \\ ${ }^{1}$ MATEIS, CNRS/INSA, 7 Avenue Jean Capelle, 69621 Villeurbanne, $F$ \\ ${ }^{2} L G G E$, CNRS/UJF, 54 rue Molière, BP 96, 38402 St Martin d'Hères, $F$ \\ *corresponding author,weiss@lgge.obs.uif-grenoble.fr
}

\begin{abstract}
We present a study of collective dislocation dynamics and plasticity during fatigue of pure Aluminum from the analysis of continuous and discrete acoustic emission (AE). The three stages of macroscopic fatigue behavior (strainhardening, shakedown, and strain softening) are clearly differentiated in terms of AE. During the first loading cycles, collective dislocation dynamics consists in dislocation avalanches of various sizes and clustered in time. Once a microstructure of dislocation cells and walls is formed, the spreading of such avalanches is restrained, and the discrete $\mathrm{AE}$ strongly decreases. Instead, a symmetrical (tension-compression) continuous AE, maximal at plastic yield, is observed, likely associated to a superposition of numerous, small and uncorrelated motions such as dislocation loops initiation from cell walls. However, some discrete AE activity remains during shakedown, a possible signature of sudden rearrangements of the microstructure occurring at scales larger than its wavelength. Finally, the onset of strain softening is associated to a strong increase of discrete $\mathrm{AE}$, in relation with microcracking. Our results suggest that collective dislocation instabilities and the emergence of a dislocation microstructure are interrelated, and challenge future numerical modeling developments of dislocation assemblies.
\end{abstract}

Keywords: fatigue, dislocations, acoustic emission, microstructure, damage

PACS: $62.20 . \mathrm{fq}, 62.20 . \mathrm{me}, 62.20 \mathrm{mt}, 61.72 . \mathrm{Hh}, 61.72 . \mathrm{Lk}$

\section{INTRODUCTION}

Fatigue is perhaps the most dangerous and simultaneously less well understood mechanism of mechanical failure encountered in a variety of modern structures ranging from nuclear reactors to micro-electronic connections in cellphones. Fatigue life prediction remains nowadays a formidable challenge, currently performed through empirical laws such as the Manson-Coffin relation. During low-cycle fatigue, plastic deformation plays an essential role, e.g. through the formation of dislocation structures such as walls and cells that result in strong strain hardening during the first cycles (e.g.[1]). These structures, which are the result of collective self-organization of dislocations[2], are assumed to be, once formed, essentially stable during the shakedown stage, and associated to an average wavelength such as the channel width [1]. Plastic deformation is accommodated through dislocation glide inside cells and, mostly, along persistent slip bands (PSB). These PSB are considered as precursors of surface or interfacial (grain boundaries) microcracking, and therefore of fatigue failure. A better understanding of collective dislocation dynamics during fatigue is therefore of primary importance.

Several years ago, acoustic emission (AE) recorded during the plastic deformation of single-crystals of ice [3-4] and metals [5] revealed the scale-free, intermittent character of plasticity, characterized by dislocation avalanches [6], time correlations [7] and fractal patterns [8]. This means, in this case, an absence of characteristic scale or wavelength. Several kinds of numerical models, either discrete [9] or continuum[10], supported this picture, raising intriguing questions regarding the modeling of plastic "flow"[10]. Experiments performed on poly-crystals revealed that grain-boundaries act as barriers to dislocation avalanches and therefore breaks down scale invariance[11]. However, all these experiments and simulations were performed under monotonous loading, with the exception of recent modeling developments, however limited to few loading cycles[12].

Here we extent our exploration of collective phenomena in plasticity from AE to fatigue loading of pure Aluminum. Pure Aluminum has been chosen as a fcc "model material" for several reasons: (i) a large initial grain size, (ii) an 
absence of precipitates and (iii) the sources of $\mathrm{AE}$ are dislocation dynamics and microcraking only (no phase transformations).

\section{METHODS AND RESULTS}

Uniaxial tension-compression $\left(\varepsilon_{\min } / \varepsilon_{\max }=-1\right)$ low cycle fatigue tests were performed at room temperature on pure aluminum $(99.95 \%)$ samples. The polycrystalline structure consisted of large elongated grains, $\sim 10 \mathrm{~mm}$ for the major axis and $\sim 3 \mathrm{~mm}$ for the minor axis. The imposed cyclic total strain amplitude $\Delta \varepsilon$ varied from $0.25 \%$ to $0.76 \%$ and the loading frequency from 0.1 to $1 \mathrm{~Hz}$. Two AE sensors (resonance frequency $140 \mathrm{KHz}$ ) were fixed on the heads of the specimens, and the AE signal was preamplified at $60 \mathrm{~dB}$. We analyzed both (i) the continuous AE measuring the "background" activity of numerous, small and likely uncorrelated dislocation motions [13], and (ii) the discrete $A E$ (hits) associated to dislocation avalanches or microcracking.

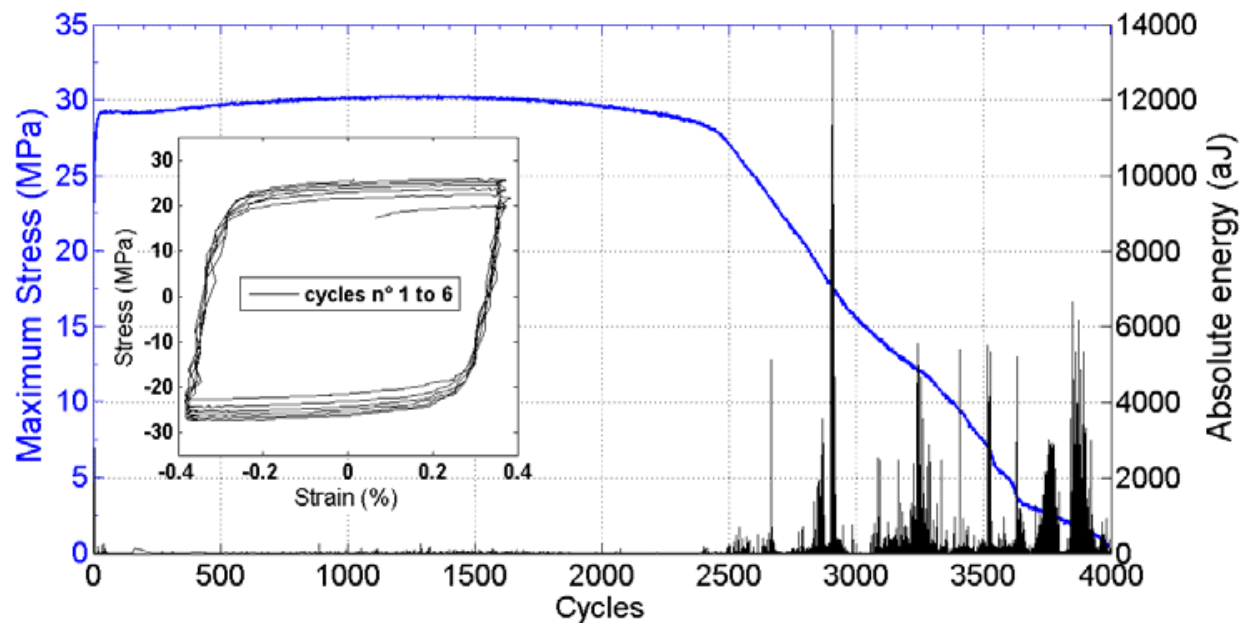

FIGURE 1. Evolution of the maximum stress during a fatigue test at $\Delta \varepsilon=0.76 \%$ (blue). The energy of acoustic hits is shown in black. Inset: Fatigue stress-strain loops

Figure 1 shows the macroscopic response (maximum stress) with the evolution of the discrete AE activity (AE energy of hits) during a test at $\Delta \varepsilon=0.76 \%$ that failed at 3991 cycles. The three classical stages of fatigue, strain hardening during the first cycles, the shakedown stage corresponding to a saturation of the stress, and the strain softening stage associated to increasing damage before failure, are clearly recovered in terms of AE. The strain hardening stage is characterized by a symmetric (tension-compression) continuous emission with a maximum of activity at plastic yield (Figure 2), and by AE hits of various sizes in both tension and compression (Figure 3). A large part of these hits occur during the first two or three cycles. Then, this discrete acoustic activity rapidly decreases as the material hardens to reach a level of 1 hit/cycle in average after 10 cycles. The shakedown stage is characterized by a continuous emission as in the first stage, and a low hit activity (still $\sim 1$ hit/cycle in average). At the onset of strain softening, discrete AE activity raises suddenly ( $\sim 10$ hits/cycle) as the result of microcracking, but is strongly asymmetrical (tension vs compression: most of the hits occur when the material is loaded only) (Figure $3)$.

\section{DISCUSSION AND CONCLUSION}

We interpret these results as follows. During the first few cycles, when the dislocation microstructure (walls, cells,..) has not been formed yet, the mean free path of collective dislocation motions (avalanches) is of the order of the large grain size $(\mathrm{mm})$. During this regime, collective dislocation dynamics share properties with monotonic loading of single crystals of ice or metals[3, 5-6]: (i) a significant intermittency (time clustering) of hits with a correlation dimension [14] of 0.8 up to the time scale of $1 / 2$ cycle and (ii) a possible power law tail for the probability density function of amplitudes, $p(A) \sim A^{-\alpha}$ with $\alpha=2.5 \pm 0.5$, this exponent value being however poorly constrained owing to the limited statistics (several hundreds of events for a given test). 


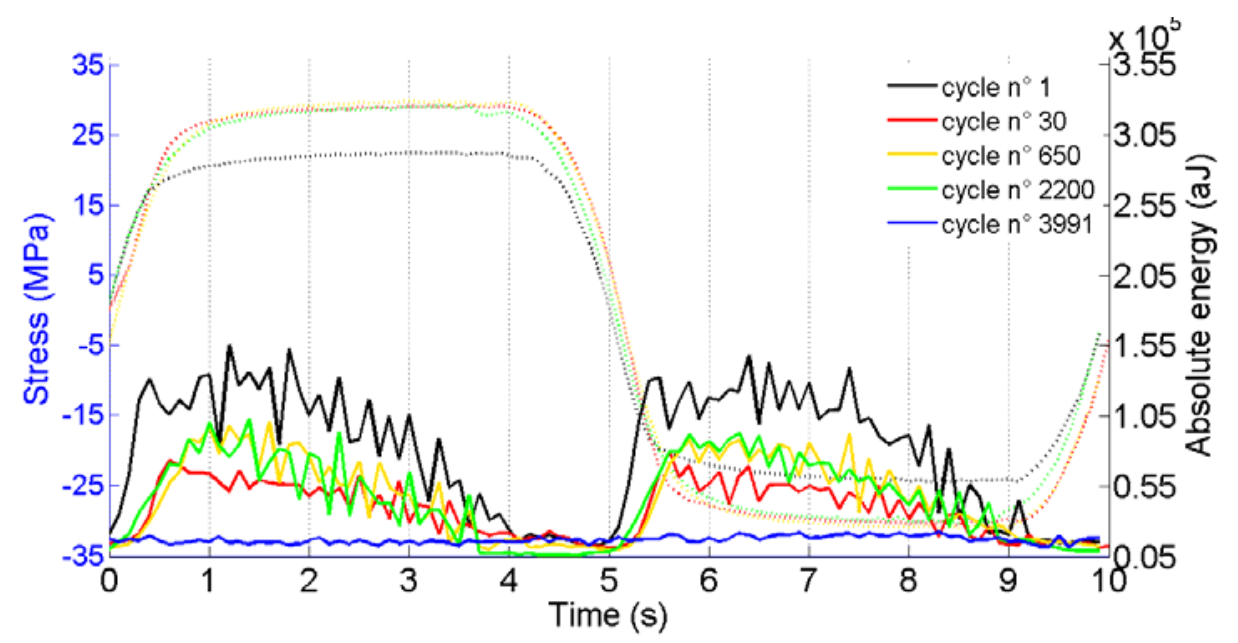

FIGURE 2. Evolution of the stress (dotted lines) and of continuous AE (solid lines) during selected loading cycles of a fatigue test at $\Delta \varepsilon=0.76 \%$. Black: First cycle. Red: End of the strain hardening stage. Yellow and green: Shakedown stage. Blue: last cycle before failure.

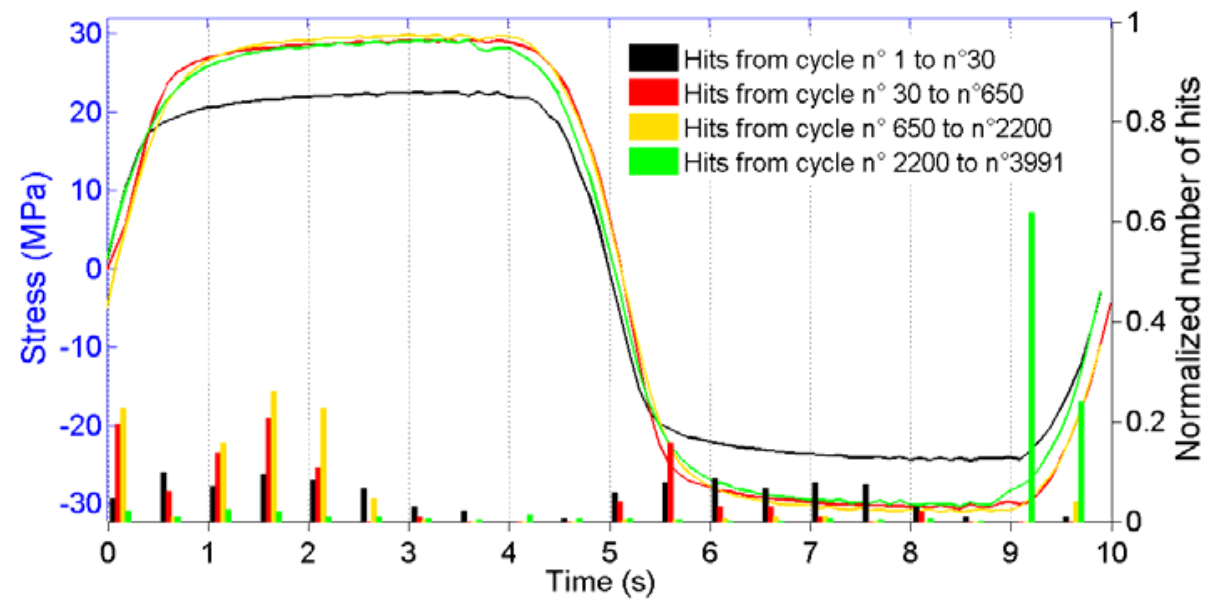

FIGURE 3. Evolution of the stress (thin solid lines) and of discrete AE (number of hits) during selected loading stages of a fatigue test at $\Delta \varepsilon=0.76 \%$. Black: Strain hardening stage. Red: shakedown stage, first part. Yellow: shakedown stage, second part. Green: strain softening stage (damage).

This dislocation avalanche activity strongly decreases as the materials hardens, in agreement with previous work that observed the emergence of a well-defined microstructure in pure Al after few fatigue cycles only [15]. The wavelength of such a microstructure is typically of few $\mu \mathrm{m}[1,16]$. If dislocation walls play the role of grain boundaries as obstacles to avalanche propagation, we expect the dislocation motion to be essentially confined within individual cells or bands, and the number of detectable avalanches to drastically decrease, as observed. In this case, most of the dislocation-related AE is restricted to continuous emission generated by a superposition of numerous, small and uncorrelated motions such as dislocation loops initiation from cell walls, as proposed by [17]. This could explain the maximum of continuous AE at plastic yield, either in tension or compression (Figure 2).

However, although weak, the hit activity does not disappear entirely during the shakedown stage. This might point out that the dislocation cell structure, once formed, is not completely "frozen". Instead, sudden rearrangements of the structure would occur at scales larger than its wavelength. Jakobsen et al. [18] observed such wall rearrangements from X-ray diffraction during the monotonic loading of pure copper. Time clustering of such events is observed at time scales below $5 \mathrm{~ms}$, i.e. a "mainshock" can be followed by several "aftershocks" over this time scale.

Finally, the raising of discrete AE activity observed from the onset of strain softening is, we believe, the signature of the onset of microcracking. The amplitudes of these events are power law distributed, with $\alpha=2.25 \pm 0.02$. 
Although preliminary, these results give new insights into collective dislocation dynamics and patterning during fatigue of fcc metals. Dislocation avalanches in one hand and microstructures on the other hand, are two expressions of collective self-organization. While the first one is of dynamical nature, the second one is considered to be "quasistatic", with great stability once established. Our results suggest instead that these two phenomena are interrelated. This will challenge future numerical modeling of dislocation ensembles. Indeed, if discrete or continuous models succeeded to simulate the intermittency of plastic flow, the emergence of dislocation structures during fatigue has eluded attempts at modeling so far (dislocation structuring has been obtained by 3D DDD simulations under monotonic loading [19]).

The next fundamental question will be that of the onset of fatigue damage, to its relation to former dislocation patterns and/or collective phenomena.

\section{ACKNOWLEDGMENTS}

This work has been supported by the French ANR-2008 grant EVOCRIT. Some fatigue tests were performed at UME laboratory of ENSTA, and we thank Z. Moumni and C. Dunand-Chatellet for technical assistance and scientific discussions. A. Constantinescu is also thanked for interesting discussions.

\section{REFERENCES}

1. Sauzay, M. and L.P. Kubin, Scaling laws for dislocation microstructures in monotonic and cyclic deformation of fcc metals. Progress in Materials Science, 2011. 56(6): p. 725-784.

2. Kubin, L.P., C. Fressengeas, and G. Ananthakrishna, Collective behaviour of dislocations in plasticity, in Dislocations in Solids, F.R.N. Nabarro and M.S. Duesbery, Editors. 2002, Elsevier: Amsterdam.

3. Weiss, J. and J.R. Grasso, Acoustic emission in single crystals of ice. J. Phys. Chem. B, 1997. 101: p. 6113-6117.

4. Weiss, J., F. Lahaie, and J.R. Grasso, Statistical analysis of dislocation dynamics during viscoplastic deformation from acoustic emission. J. Geophys. Res., 2000. 105(B1): p. 433-442.

5. $\quad$ Richeton, T., et al., On the critical character of plasticity in metallic single crystals. Mat. Sci. Eng. A, 2006. 424: p. 190-195.

6. Miguel, M.C., et al., Intermittent dislocation flow in viscoplastic deformation. Nature, 2001. 410: p. 667-671.

7. Weiss, J. and M.-C. Miguel, Dislocation avalanche correlations. Mat. Sci. Eng. A, 2004. 387-389(292-296).

8. Weiss, J. and D. Marsan, Three dimensional mapping of dislocation avalanches: clustering and space/time coupling. Science, 2003. 299(5603): p. 89-92.

9. $\quad$ Miguel, M.-C., et al., Complexity in dislocation dynamics: model. Mat. Sci. Eng. A, 2001. 309-310: p. 324-327.

10. Zaiser, M., Scale invariance in plastic flow of crystalline solids. Advances in Physics, 2006. 55: p. 185-245.

11. Richeton, T., J. Weiss, and F. Louchet, Breakdown of avalanche critical behaviour in polycrystalline plasticity. Nature Materials, 2005. 4: p. 465-469.

12. Salman, O.U. and L. Truskinovsky, Minimal Integer Automaton behind Crystal Plasticity. Physical Review Letters, 2011. 106(17).

13. Rouby, D., P. Fleischman, and C. Duvergier, Un modèle de source d'émission acoustique pour l'analyse de l'émission continue et de l'émission par salves: I. Analyse théorique. Philosophical Magazine A, 1983. 47(5): p. 671-687.

14. Kagan, Y.Y. and D.D. Jackson, Long-term earthquake clustering. Geophys. J. Int., 1991. 104: p. 117-133.

15. Chicois, J., et al., THE MOBILITY OF DISLOCATIONS DURING THE CYCLIC ATTRACTION OF POLYCRYSTALLINE ALUMINUM. Acta Metallurgica, 1986. 34(11): p. 2157-2170.

16. Zhai, T., J.W. Martin, and G.A.D. Briggs, Fatigue damage at room temperature in aluminium single crystals .2. TEM. Acta Materialia, 1996. 44(5): p. 1729-1739.

17. Slimani, A., P. Fleischmann, and R. Fougères, Etude par émission acoustique de la dynamique des dislocations pendant la déformation cyclique de polycristaux d'aluminium. J. Phys. III France, 1992. 2: p. 933-945.

18. Jakobsen, B., et al., Formation and subdivision of deformation structures during plastic deformation. Science, 2006. 312: p. 889-892.

19. Devincre, B., L. Kubin, and T. Hoc, Collinear superjogs and the low-stress response of fcc crystals. Scripta Materialia, 2007. 57(10): p. 905-908. 